\title{
HISTÓRIA E ESTRUTURA \\ EM MAURICE MERLEAU-PONTY E CLAUDE LÉVI-STRAUSS
}

\author{
Davide Scarso
}

Esta minha comun icação, ao esboçar uma comparação entre o pensamento de Merleau-Ponty e o pensamento de Lévi-Strauss a partir das suas atitudes face a história, pretende de alguma forma celebrar um duplo centenário: os cem anos de nascimento de Merleau-Ponty e o centésimo aniversário de Lévi-Strauss.

A distância entre as posições de Merleau-Ponty e de Lévi-Strauss sobre a história não é apenas deduzível de forma indirecta, sendo que, o próprio filósofo a aborda de maneira directa. Numa note de travail de Le Visible et l'Invisible ${ }^{1}$ de Setembro de 1959 (intitulada 'Pregnance, Transcendance') Merleau-Ponty formula a intenção de retomar, numa futura redacção do texto, a sua crítica da noção de gestaltung tal como foi elaborada por Lévi-Strauss. ${ }^{2}$

Claude Lefort, responsável pela edição do livro que a morte de Merleau-Ponty deixou incompleto, comenta estas linhas lamentando o facto de não ter conhecimento da crítica que aí se refere e que provavelmente o filósofo terá desenvolvido num curso ou numa nota pessoal. De qualquer forma, Lefort remete para o que julga ser o objecto desta crítica, ou seja, a elaboração da distinção entre história cumulativa e história não cumulativa que Lévi-Strauss propôs em Race et histoire. ${ }^{3}$

${ }^{1}$ Merleau-Ponty, M., Le Visible et l'Invisible, Paris: 'Gallimard, 1964, p. 260. Apresentámos uma primeira aborlagem a este tema in Scarso, "Merleau-Ponty, Lévi-Strauss e la percezione sociale", Chiasmi International 7, 2005, pp. 371-391.

2 "[reproduire ici ma critique de l'explication de la gestaltung chez Lévi-Strauss par la mise en commun des chances, par la rencontre - oui il faut rencontre, mais ce qui s'élabore par cette rencontre, la matrice symblique de l'Occident n'est pas un produit de la causalité]. Montrer que, la Gestalt surgissant du polymorphisme, cela nous situe tout à fait hors de la philosophie du sujet et de I'objet." Merleau-Ponty, M., Le Visible et l'Invisible, ed. cit., p. 26.

${ }^{3}$ Lévi-Strauss, Race et histoire. Paris: Unesco, 1952, depois in Lévi-Strauss, Anthropologie structurale deux, cit., pp. 377-422. 
A recente publicação das transcrições dos cursos no Collège de France do ano $1954-55,{ }^{4}$ em particular do primeiro relativo a L'institution dans l'histoire personelle et publique, coloca-nos em condições de trazer alguma luz à questão e reconstruir a crítica que Merleau-Ponty dirige a Lévi-Strauss naquele curso.

$*$

Em Race et histoire Claude Lévi-Strauss propôs-se demonstrar como a origem da diferença entre culturas não depende de qualidades intrínsecas, mas é antes o produto de uma série de condições totalmente casuais. Noutras palavras, para Lévi-Strauss, é absolutamente impossível colocar as diferentes civilizações numa hierarquia.

Julgamos que haja culturas que progridem incessantemente e que são cumulativas, ou seja que acumulam invenções, tecnologias, energia, que tornam possíveis mais invenções, mais tecnologias, mais energia, como a nossa, e outras que por alguma razão pararam numa certa fase do seu desenvolvimento, que são estacionárias, como no caso dos povos tradicionais. Mas, na realidade, trata-se de uma ilusão, avança Lévi-Strauss, sendo que o nosso juízo é inteiramente dependente do nosso ponto de vista. Julgamos cumulativa a história de um grupo humano que esteja a desenvolver-se no mesmo sentido da nossa própria história, enquanto nos aparece como estacionária uma história que se mova numa direcção diferente. È um pouco o que acontece no famoso exemplo do comboio utilizado por Einstein para ilustrar como, no âmbito da teoria da relatividade, as dimensões e a velocidade não sejam valores absolutos, mas dependam da posição do observador. ${ }^{5}$ Para um viajador sentado num comboio perto da janela, a velocidade e o comprimento dos comboios que lhe passam ao lado variam consoante eles se movam na mesma direcção ou em direcção oposta à do primeiro: “Or, toute membre d'une culture en est aussi étroitement solidaire que ce voyageur idéal l'est de son train". ${ }^{6}$ Analogamente, o juízo que nós formulamos acerca do desenvolvimento histórico de uma sociedade diferente, como também a própria ideia de história que empregamos, dependem inteiramente daquele sistema de referências que o ambiente em que fomos educados e em que vivemos "fait pénétrer en nous, par mille démarches conscientes et inconscientes". ${ }^{\prime}$

${ }^{4}$ Merleau-Ponty, M., L'institution -La passivité. Notes de cours au Collège de France (1954-1955), Paris: Belin, 2003.

${ }^{5}$ Cf., por exemplo, o capítulo "The relativity of simultaneity", in Einstein, Albert/Lawson, Robert W., Relativity: The Special and the General Theory. London: Routledge, 2001, pp. 19 ss.

${ }^{6}$ Merleau-Ponty, M., L'institution-La passivité, ed. cit., p. 397.

${ }^{7}$ Ibid. 
Do ponto de vista da energia disponível per capita, que é característica do Ocidente "maître des machines", alguns grupos humanos podem de facto dar a impressão de serem caracterizados por uma história estacionária, no entanto, estes mesmos grupos podem revelar-se completamente cumulativos no que diz respeito, por exemplo, à sua produção artística. Se tomássemos como critério a adaptação a condições geográficas desfavoráveis, seriam então os Esquimós e os Beduínos a conseguirem os resultados mais consideráveis. Do ponto de vista do pensamento filosófico e religioso, o primado pertence à Índia. Mais ainda, tomando em consideração a complexidade das suas regras de parentesco e a refinação com que foi formalmente elaborado, são sem dúvida, os Australianos que detêm a primazia nesta área, apesar de possuírem uma cultura técnica bastante primária. Em consequência desta pluralidade de perspectivas, chegar a uma hierarquia definitiva das diferentes culturas humanas requereria, de acordo com o autor, a assunção contemporânea de todos os pontos de vista possíveis:

pour débrouiller un échevaux formé de fils aussi nombreux et ténus, il ne faudrait pas faire moins que soumettre la société considérée (et aussi le monde qui l'entoure) à une étude ethnographique globale et de tous les instants. ${ }^{8}$

O que seria manifestamente impossível. É verdade que, a uma observação atenta, todos os grupos humanos produzem algum tipo de inovação e são portanto, de alguma forma, cumulativos. ${ }^{9}$ Só que, na maior parte dos casos, as acumulações não comportam modificações significativas, enquanto noutros casos, porém bastante raros, dão lugar a uma "réaction en chaîne". ${ }^{10}$

Aqui o antropólogo introduz a sua argumentação chave, que ilustra recorrendo à metáfora da roulette. No jogo da roulette a saída de uma série de dois números consecutivos é relativamente frequente, enquanto uma série de três números já é muito menos frequente e ainda mais rara será uma série de quatro números e assim por diante:

Un joueur... qui ne parierait jamais que sur les séries le plus longues (de quelque façon qu'il conçoive ces séries), aurait toute chance de se ruiner. Il n'en serait pas de même d'une coalition de parieurs jouant les mêmes séries en valeur absolue, mais sur plusieurs roulettes et en s'accordant le privilège de mettre en commun les résultats favorables aux combinaisons de chacun. ${ }^{11}$

Uma série muito comprida de números consecutivos na roulette corresponde àquela combinação de requisitos que permitem um salto cultural radical, e isto, como é óbvio, sempre do ponto de vista do nosso sistema de referência,

8 Ibid., p. 407.

9 Ibid., p. 411.

10 Ibid., p. 409.

11 Ibid., p. 412. 
sendo que outras culturas poderão interpretar como séries algumas sequências de números que aos nossos olhos aparecem sem nenhum tipo de relação.

Uma sociedade com história estacionária, aliás, com uma história menos cumulativa, deriva esta sua característica simplesmente do facto de ser isolada, enquanto uma sociedade cumulativa goza do privilégio de estar em contacto com grupos muito diferentes. Ou seja, algumas culturas tiveram a vantagem de poder estabelecer coligações mais extensas e mais duradouras face às conseguidas pelas outras. A América pré-colombiana, por exemplo, era habitada por numerosas culturas que mantinham intensos contactos entre si. Porém, por outro lado, todas elas descendiam daquela única estirpe que havia povoado o continente americano em tempos relativamente recentes. Inversamente, as sociedades que existiam na Europa renascentista e que, de maneira análoga, gozavam de intensas trocas recíprocas, distinguiam-se entre si por tradições muito mais longas. Tal significa, de acordo com Lévi-Strauss, que as primeiras tenham sido muito menos cumulativas do que as segundas e que portanto houvesse uma probabilidade maior que uma revolução, uma reacção em cadeia, ou seja, uma longa série de números consecutivos na metáfora da roulette, se realizasse na Europa ocidental.

A dependência de um sistema de referências próprio da nossa cultura e ao qual não nos podemos subtrair, assim como a impossibilidade de destrinçar a intricada meada formada pelos inúmeros fios da história, levam Lévi-Strauss, como vimos, a introduzir a noção de probabilidade. Ou seja, nota o filósofo, se por um lado se afirma a ideia da opacidade total da história e do mundo social, por outro lado, introduz-se, o ponto de vista de um observador absoluto recorrendo ao cálculo combinatório.

Perante 'o olhar distanciado do cientista social "le social est objet" 12 e não se dá nenhuma diferença entre os eventos: "Les séries des événements sont probabilité et hasard. [Ici ou là a lieu] une agglomération de événements." 13

O relativismo que o antropólogo propõe é de certa forma o oposto complementar de uma ideia de saber absoluto que continua, apesar de tudo, a ser a referência fundamental, na forma de uma sociologia entendida como coincidência com o ser social. Precisamente no momento em que declara a impenetrável opacidade da superfície histórica dos fenómenos sociais, Lévi-Strauss acaba por colocar-se na posição de um espectador absoluto, Kosmotheoros de acordo como o termo privilegiado por Merleau-Ponty. O relativismo absoluto que caracteriza as culturas humanas pode ser reconhecido na sua plena verdade unicamente perante o olhar do cientista social, do antropólogo, em última análise do filósofo, na sua "solitude radicale, pensée exhaustive". ${ }^{14}$ Enquanto os 
sujeitos que vivem no seu interior assumem cada um a sua como sistema de referência absoluto.

Observamos como o antropólogo ilustra a noção do pluralismo impenetrável das culturas recorrendo à imagem do viajante no comboio, exemplo utilizado na explicação da teoria da relatividade. Por sua vez, Merleau-Ponty retoma justamente um dos argumentos principais da crítica que Henri Bersgon dirige a Einstein em Durée et simultaneité ${ }^{15}$ ainda que não o refira expressamente: "Un relativisme plus radical". ${ }^{16} \mathrm{O}$ relativismo deve chegar a fazer a sua própria autocrítica para poder ir além do mero cepticismo histórico, e será portanto necessário de alguma forma relativizar o relativismo:

Il faut être plus Einstein qu'Einstein et rétablir le monde de la perception avec ses «simultanéités» - de même il faut être plus relativiste que Lévi-Strauss et replacer le savoir dans le monde de la perception historique avec les opérations de «compréhension». ${ }^{17}$

Merleau-Ponty, que se refere de forma implícita a $A$ Ética protestante $e$ o espírito do capitalismo, ${ }^{18}$ observa que também para Max Weber o encontro casual entre determinados caracteres culturais é fundamental. Para que o capitalismo surgisse era necessária a presença contemporânea de "direito, Estado, religião, Ciência, trabalho livre, contabilidade etc." ${ }^{19}$ No entanto, de acordo com o sociólogo alemão, a partir do encontro entre estes caracteres estabelece-se um sistema que possui uma lógica própria, um autêntico Kosmos. O sociólogo alemão parte assim duma posição que em muitos aspectos é análoga à de Lévi-Strauss, e que opõe, como vimos, o espírito e as suas intrínsecas limitações à opacidade impenetrável da história, uma meada que não é possível destrinçar sendo composta por tantos fios e tão subtis. De acordo com Merleau-Ponty, o percurso que é possível vislumbrar nas obras de Weber é muito mais válido e produtivo indicando-nos algo como uma relativização do relativo.

Noutras palavras, Merleau-Ponty parece estar a sugerir que uma possível solução para os problemas inerentes à posição de Lévi-Strauss poderá ser procurada na obra de Weber. O sociólogo tinha sido objecto de uma aprofundada leitura no âmbito do curso do ano anterior, intitulado 'Materiaux pou une thé-

15 Bergson, Henri, Durée et simultanéité. Paris: Alcan, 1922 e, depois, Paris: PUF, 1998.

${ }^{16}$ Ibid., p. 117

17 Ibid.

18 Weber,Max, "Die protestantische Ethik und der Geist des Kapitalismus", Archiv für Sozialwissenschaft und Sozialpolitik xx-xxI, 1904-1905 e, depois, Gütersloh: Gerd Mohn, 1979 (trad. it. de G. Galli, L'Etica protestante e lo spirito del capitalismo. Milano: Rizzoli, 1996).

19 Merleau-Ponty, M., L'institution-La passivité, ed. cit., p. 45. 
orie de l'histoire', ${ }^{20}$ como também no ensaio Les aventures de la dialectique, ${ }^{21}$ redigido ainda entre 1953 e 1954.

Observa no curso do Collège, que o ponto de partida de Max Weber presta de facto a maior atenção à inexaurível multiplicidade de perspectivas (Vielseitigkeit) que a história nos apresenta, à "contingence radicale et à l'infinité du fait historique". ${ }^{22}$ Com efeito, de acordo com uma direcção 'kantiana', a objectividade histórica torna-se portanto um correlativo da actividade mental do historiador deparando-se com a inexauribilidade da história, e permanece portanto essencialmente provisória e em perene e necessária confrontação com pesquisas ulteriores e outros pontos de vista.

Weber estabelece então uma oposição entre o saber -que, enquanto 'objectividade construída', será sempre provisório e condicionado-e a prática, entendida como "la tache infinie d'évaluer l'évent même". ${ }^{23}$ À partida, não há comunicação possível entre estes dois universos e teoria e prática requerem critérios de justificação completamente heterogéneos: "Cette attitude est une constante de sa carrière. Elle fait de l'histoire une sorte de maléfice." 24

Merleau-Ponty salienta que Weber, no entanto, nas suas pesquisas concretas, não se mantém adstrito a esta rigorosa dicotomia e parece reconhecer que se trata no fundo de limites abstractos "entre lesquels, bon gré mal gré, notre vie opère une médiation". ${ }^{25}$ Nos seus comentários, o filósofo refere-se em particular a Die protestantische Ethik, obra em que Weber "entre dans l'intérieur du fait historique beaucoup plus que ses principes «kantiens» ne le comportaient". ${ }^{26}$ Desta forma, acaba por ultrapassar de facto o contraste tenaz entre os limites do intelecto e o perspectivismo infinito da história e passa da construção do intelecto à 'compreensão'.

O filósofo observa que com o seu trabalho sobre a ética protestante, Weber pretende em primeiro lugar colocar em evidência a existência de eventuais relações entre ética profissional e formas de fé religiosa, sem por isso as reconduzir necessariamente a relaçẽes casuais. O sociólogo, diz Merleau-Ponty, prefere antes falar de "parentés de choix", ou de afinidades electivas (Wahlverwandschaften ${ }^{27}$ ).

${ }^{20}$ Merleau-Ponty, M., Résumés de cours (Collège de France, 1952-1960). Paris: Gallimard, 1968.

${ }^{21}$ Merleau-Ponty, M., Les aventures de la dialectique. Paris: Gallimard, 1955.

22 Merleau-Ponty, M., Résumés de cours, ed cit., p. 47.

23 Ibid.

${ }^{24}$ Ibid., p. 48.

${ }^{25}$ Ibid.

${ }^{26}$ Ibid., p. 49.

27 O facto de Merleau-Ponty recorrer sempre à expressão "parenté de choix" em vez de "affinités électives" leva-nos a crer que possa não ter tido consciência da inspiração goethiana latente nas palavras de Weber. Michel Löwy, no seu artigo "Le concept d'affinité élective en sciences sociales" (Critique internationale 2, hiver 1999, p. 44) fornece a seguinte definição da noção 
É precisamente no contacto entre si que estas diferentes opções puderam concorrer na formação do capitalismo ocidental. A essência do sistema, portanto, não preexiste a este encontro. ${ }^{28}$ Desta forma, se à partida a Vielseitigkeit da história - ou seja, a inexaurível plưralidade de aspectos que um acontecimento possui, os numerosos fios da meada de que fala Lévi-Strauss-representaria também para Weber o obstáculo onde todo o projecto de um conhecimento histórico objectivo vai fatalmente esbarrar, pode agora tornar-se

justement ce qui agglomère la poussière des faits, ce qui permet de lire dans un fait religieux la première esquisse d'un système économique, dans un système économique des prises de position à l'égard de l'absolu. ${ }^{29}$

A opacidade da história não é portanto completamente removida, porque entre os diferentes elementos de uma totalidade histórica Weber não pretende estabelecer relações unívocas, mas sim afinidades, uma vez que todos estes elementos pertencem em última analise à "trame unique des choix humaines". ${ }^{30}$

Na convicção de Merleau-Ponty, Weber procura então manter-se a meio caminho entre a história considerada como uma série de acontecimentos pontuais - que é "indifférente, agnostique, qui aligne les civilisations comme des individus incomparables" - e uma filosofia que alimenta a ilusão de poder "d'enfermer le passé dans ses catégories et le réduit à ce que nous en pensons". ${ }^{31} \mathrm{O}$ nosso autor revela que o que permite ultrapassar esta antinomia é justamente "notre intérêt pour le passé: il est nôtre et nous sommes siens, rien ne peut faire que les drames qui ont été vécus ne nous parlent des nôtres et de nous". ${ }^{32}$ Já ao querer compreender o passado o historiador introduz inevitavelmente uma certa ordem nos factos "les situer dans une hiérarchie, dans un progrès ou dans une régression" e, desta forma, acaba por retomar "le mouvement même du passé". ${ }^{33}$

de afinidade electiva: "il s'agit du processus par lequel deux formes culturelles - religieuses, littéraires, politiques, économiques, etc. - entrent, à partir de certaines analogies ou correspondances structurelles, en un rapport d'influence réciproque, choix mutuel, convergence, symbiose et même, dans certains cas, fusion".

${ }^{28}$ Merleau-Ponty, M., Résumés de cours, ed. cit., p. 48. Cf. também Merleau-Ponty, M., Les aventures de la dialectique, ed. cit., p. 28.

${ }^{29}$ Merleau-Ponty, M., Les aventures de la dialectique, ed. cit., p. 31. "Le pluralisme, qui semblait interdire toute interprétation unifiante de l'histoire, prouve au contraire la solidarité de l'ordre économique, de l'ordre politique, de l'ordre juridique, de l'ordre moral ou religieux, à partir du moment où même le fait économique est traité comme choix d'un rapport avec les hommes et avec le monde, et prend sa place dans la logique des choix." (Merleau-Ponty, M., Résumés de cours, ed. cit., p. 50). 
No momento em que "l'entendement découvre dans son objet sa propre origine", ${ }^{34}$ a história deixa de ser a simples oposição entre a subjectividade do intelecto e a objectividade do passado: "Notre contact avec notre temps est une initiation à tous les temps, l'homme est historien parce qu'il est historique, l'histoire n'est que l'amplification de la pratique". ${ }^{35}$ A própria ideia de um conhecimento histórico que seja objectivo pertence a um determinada época da história e é uma das componentes daquele amplo processo de racionalização que é, para Weber, o aspecto fundamental da sociedade capitalista. ${ }^{36}$ Os tipos ideais, que o historiador introduz para permitir a formação de uma imagem determinada do passado, representariam o fosso intransponível que o separa da infinita riqueza do acontecimento somente se fossem completamente arbitrários. Mas mesmo os próprios tipos ideais pertencem ao devir histórico: "l'histoire science, avec ses méthodes, ses idéalisations, est un aspect de l'histoire réalité, de la rationalisation capitaliste". ${ }^{37} \mathrm{O}$ movimento de compreensão histórica realiza-se então neste gesto em que a história se desdobra sobre si própria procurando "de se saisir, de se dominer, de se faire raison". ${ }^{38}$ Por outro lado, tendo lugar num estrito contacto com a contingência, o êxito deste gesto não é nunca garantido.

Analogamente ao que acontecia no caso da dupla figura/fundo da psicologia gestaltista, os tipos ideais weberianos são desta maneira restituídos ao fundo histórico a que pertencem e que os torna percepcionáveis. Deixam então de ser meras construções do intelecto e tornam-se, nas palavras de Merleau-Ponty, as matrizes simbólicas ou os núcleos inteligíveis em cujo redor gravita o "infini detail des facts": ${ }^{39}$

Ces noyaux intelligibles de l'histoire sont des manières typiques de traiter l'être naturel, de répondre aux autres et à la mort. Au point de contact entre les hommes et les données de la nature ou du passé apparaissent comme des matrices symboliques qui ne préexistent nulle part, et qui peuvent, pour un temps ou pour longtemps, mettre leur marque sur le cours des choses puis disparaître sans que rien les ait détruites de front, par désagrégation interne, ou parce que quelque formation secondaire y devient prédominante et les dénature. La «rationalisation» par laquelle Weber définit le capitalisme est une de ces structures fécondes qui se lisent aussi bien dans l'art, dans la science ou dans l'économie de l'Occident. ${ }^{40}$

${ }^{34}$ Merleau-Ponty, M., Résumés de cours, ed. cit., p. 51.

35 Ibid., p. 50.

36. Cf. Merleau-Ponty, M., Les aventures de la dialectique, ed. cit., p. 33. Aqui Merleau-Ponty remete para o ensaio de Löwith, Karl, "Max Weber und Karl Marx", em Archiv für Sozialwissenschaft und Sozialpolitik 67, 1932, pp. 53-99 e 175-214 e, depois, in Löwith, Karl, Gesammelte Abhandlungen. Zur Kritik der geschitlichen Existenz. Stuttgart: W. Kohlammer, 1960, pp. 1-67.

37 Merleau-Ponty, M., Les aventures de la dialectique, ed. cit., p. 46.

38 Ibid., p. 38.

39 Merleau-Ponty, M., Résumés de cours, ed. cit., p. 51.

${ }^{40}$ Merleau-Ponty, M., Les aventures de la dialectique, ed. cit., p. 28, sublinhados nossos. 
Merleau-Ponty reconhece de qualquer maneira, como se torna mais evidente em Les aventures de la dialectique, que Weber tem o mérito de indicar este percurso de relativização do relativismo, mas por outro lado, não o acompanha até ao fundo. O autor da Die protestantische Ethik permaneceu ligado, apesar de tudo, a uma ideia de verdade entendida como ausência de condições e eliminação do ponto de vista. Comparado com esta verdade objectiva, embora ela continue a ser constitutivamente inalcançável, este nosso saber tacteante e progressivo acaba sempre por ser encarado como algo do mesmo género da opinião e da aparência. Aquela nova filosofia da história sem dogmatismos que Merleau-Ponty procura está de alguma maneira anunciada na obra de Weber, mas é necessário forçar a sua letra e "intérpreter librement" para a poder encontrar. ${ }^{41}$

Quem teve consciência desta possibilidade e a procurou articular foi György Lukács. O filósofo húngaro (1885-1971) viveu desde 1912 em Heidelberg, e foi aluno de Heinrich Rickert e em vários aspectos foi também um aluno de Max Weber do qual se tornou muito próximo. Foi Lukács que pretendeu retomar o movimento circular entre prática e teoria, entre presente e passado e que o seu mestre tinha de alguma forma indicado. $\mathrm{O}$ conhecimento e a actividade prática seriam ao mesmo tempo "solidales et ouvertes" 42 e, longe de constituir algo como uma totalidade concluída perante o olhar destacado de um espectador, configura-se como "tâche de totalisation". ${ }^{43} \mathrm{O}$ que Lukacs procura pois mostrar em Geschichte und Klassenbewusstsein, ${ }^{44}$ comenta Merleau-Ponty, é que, se conduzirmos o desdobramento da história sobre si própria até ao limite, poderemos então chegar a "un absolu dans le relatif" ${ }^{45}$

No entanto, se Weber por seu turno não tinha chegado suficientemente adiante, quando Lukács toma o proletariado como "foyer du processus social" e o julga capaz de vir a construir "une societé que soit vraiment société, transparente, sans cloisonnement intérieurs, sans classe" 46 acaba por avançar demasiado. Em consequência, aquela "potence de doute e d'interrogation" a que Weber se referia com a palavra cultura, é aqui personificada pelo proletariado, que se torna então "l'incarnation dans l'histoire de la negativité" . ${ }^{47}$ Para Merleau-Ponty esta também não é uma solução desejável, porquanto a ideia de uma negatividade realizada num sujeito histórico concreto acaba por desvirtuar toda a noção de um sentido imanente à história. As diferentes épocas históricas, para o filósofo, coagulam-se em volta de um certo modo de formular uma

${ }^{41}$ Ibid., p. 27.

42 Merleau-Ponty, M., Résumés de cours, ed. cit., p. 56.

43 Merleau-Ponty, M., Les aventures de la dialectique, ed. cit., p. 48.

44 Lukács, Gyorgy, Geschichte und Klassenbewusstsein. Studien über marxistische Dialektik. Berlin: Der Malik-Verlag, 1923.

45 Merleau-Ponty, M., Les aventures de la dialectique, ed. cit., p. 47.

46 Merleau-Ponty, M., Résumés de cours, ed. cit., p. 54.

${ }^{47}$ Ibid., p. 56. 
"interrogation sur la possibilité de l'homme". ${ }^{48}$ Mas a interrogação mantêm-se e nenhuma solução se impõe enquanto tal: "c'est dans une interrogation permanente que tous les temps composent ensemble une seule et universelle histoire". ${ }^{49}$

A sugestão da possibilidade de uma aproximação diferente ao saber histórico está já portanto presente em Weber, que a intui sem todavia a desenvolver de forma temática. Será então Lukács que a reclama e articula plenamente, porém, ao a materializar anula as suas potencialidades. Mas, de qualquer forma, os dois têm o grande mérito de permitir repensar o problema da história evitando reduzi-la, por um lado, a uma mera sequência de factos equivalentes entre eles e, por outro, a um "dieu exterieur" ou a uma "raison cachée" ${ }^{50}$ De acordo com Merleau-Ponty, é possível, e necessário, evitar estes dois impasses, simultaneamente opostos e complementares, e encontrar uma nova forma de pensar a história, que se torna assim:

c'est ce fait métaphysique que la même vie, la nôtre, se joue en nous et hors de nous, dans notre présent et dans notre passé, que le monde est un système à plusieurs entrées ou, comme on voudra dire, que nous avons des semblables. ${ }^{51}$

Esta elaboração move-se, com efeito, na mesma perspectiva daquela nova filosofia da história que talvez já Saussure, salienta Merleau-Ponty, poderia ter intuído: "une théorie du sens historique qui passe outre à l'alternative des choses et des consciences". ${ }^{52}$ Uma interrogação autêntica da história deve portanto distanciar-se de a considerar como uma essência objectiva como também de pressupor algo com uma constituição subjectiva dè sentido. ${ }^{53}$

Está justamente aqui o ponto de partida de toda a reflexão de Merleau-Ponty acerca da noção de înstituição, que procura justamente enfrentar o "vieux problème des rapports du sujet et de l'objet" que os seus trabalhos sobre a linguagem e a história levantaram. O conceito de instituição, que é como que uma tradução e reinterpretação da noção husserliana de Stiftung, é introduzido por Merleau-Ponty no propósito de mostrar que o sentido não é constituído pela consciência, mas se autoconstitui. ${ }^{54} \mathrm{~A}$ instituição corresponde então ao emergir de uma matriz simbólica que permite a "ouverture d'un champ, d'un avenir selon [des] dimensions, d'où possibilité d'une aventure commune et d'une histoire comme conscience". ${ }^{55}$

${ }^{48}$ Merleau-Ponty, M., Les aventures de la dialectique, ed. cit., p. 39.

49 Merleau-Ponty, M., Résumés de cours, ed. cit., p. 52.

${ }^{50}$ Merleau-Ponty, M., Les aventures de la dialectique, ed. cit., p. 27.

51 Ibid., p. 35.

52 Merleau-Ponty, M., Éloge de la philosophie. Paris: Gallimard, 1971, p. 56.

53 Neri, Guido D., "Storia e possibilita", in Aut Aut 232-233, 1989, agora in Neri, Guido D., Il sensibile, la storia, l'arte. Verona: Ombre Corte, 2003, pp. 219-220; p. 214.

${ }^{54}$ Carbone, Ai confini dell'esprimibile, cit., p. 107.

${ }^{55}$ Merleau-Ponty, M., L'institution-La passivité, ed. cit., p. 45. 
Frequentemente o antropólogo usa de facto uma linguagem ligada de forma estrita à experiência vivida, frisa Merleau-Ponty, como quando diz, por exemplo, que os diferentes sistemas de parentesco podem jogar pelo seguro ou adoptar uma atitude mais aventurosa. ${ }^{56}$ Contudo em cada um destes casos explica de imediato que se tratam unicamente de metáforas, retirando-lhes qualquer valor substancial. ${ }^{57}$ As leis do mundo social, tal como as leis do mundo físico, não carecem da nossa presença para poder funcionar: "[l']atome n'a pas besoin de connaître [les] lois pour les suivre". ${ }^{58}$ A perspectiva absoluta de Lévi-Strauss mantém como referência constante um saber absoluto, colocado fora de qualquer situação, enquanto, defende Merleau-Ponty, o conhecimento é sempre histórico e impuro e o seu objecto é um devir do sentido: ${ }^{59}$

C'est le problème déjà posé par Gestalttheorie: il faudrait se demander ce que signifie "gravitation» sociale hors non pas de toute pensée, mais de toute vie. ${ }^{60}$

Quando o antropólogo escreve que as relações de reciprocidade nos sistemas de troca generalizada são "relations orientées", ${ }^{61}$ cuja direcção depende do ponto de vista de quem as pratica, está de certa forma a denunciar as operações de compreensão que sustentam o seu discurso. Muito provavelmente contra a sua própria vontade, revela aqui que o conhecimento, antes de ser um confronto entre um sujeito e um objecto, é mais próximo a um "comparaison comme de deux choses vues" 62 e abre o caminho a uma possível sociologia fenomenológica. As metáforas de Lévi-Strauss deverão portanto ser lidas de forma literal e teremos que reconhecer que também o espaço social é orientado perceptivamente:

Comme la chose perçue est principe de cohésion vécue sans être essence, le sys- tème symbolique, le pattern, serait chose sociale. Une société [est] perçue comme une chose, - et, comme une chose, n'est jamais «pure». ${ }^{63}$

Tal como verificámos nos capítulos anteriores, para Lévi-Strauss o inconsciente é um conjunto de leis formais universais cujo estatuto, ao mesmo tempo individual e colectivo, permite e garante a comunicação directa entre a cons-ciência subjectiva do observador e o comportamento objectivo dos observados. De acordo com Merleau-Ponty, o inconsciente deve pelo contrário ser

56 Cf., por exemplo, Lévi-Strauss, Les structures élémentaires de la parenté, p. 51 e p. 396.

57 Merleau-Ponty, M., L'institution-La passivité, ed. cit., p. 120.

58 Ibid., 116.

59 Ibid., p. 107.

60 Ibid., p. 116, sublinhado nosso.

${ }^{61}$ Lévi-Strauss, structures élémentaires de la parenté, cit., p. 206.

62 Ibid., p. $107 \mathrm{n}$.

${ }^{63}$ Merleau-Ponty, M., L'institution-La passivité, cit., p. 121. 
interpretado como "fondement perceptif" ${ }^{64}$ As ciências sociais mais não fazem de que desenvolver as implicações da percepção social e destacar os centros de inteligibilidade que nela surgem. Como fazem também, por outro lado, a lógica, a matemática e a própria fenomenologia. Mas tudo o que estas disciplinas trazem à expressão continua a ser expressão de ..., e não se trata simplesmente da extracção de um conteúdo que estava desde sempre já presente mas de uma "idéalisation qui a un autre sens d'être que l'exprimé" 65

O sistema objectivo que a antropologia de Lévi-Strauss julga encontrar por baixo dos fenómenos é na realidade uma construção artificial, as estruturas do parentesco não são interpretadas como essências, mas como "styles de coexistence" ${ }^{66}$ O saber sociológico deve portanto ser entendido como a idealização da nossa percepção social, da mesma forma como a geometria ou as leis da perspectiva são idealizações da nossa percepção visual. O sistema que derivamos desta operação de idealização será fundado:

non dans [un] entendement divin qui serait «le réel» (pour Lévi-Strauss comme pour Engels), non sur [une] «finalité» d'essences travaillant derrière notre dos, mais sur [la] configuration sociale qui serait l'appareil symbolique de cette intersubjectivité $^{67}$

Para o filósofo, a abordagem estrutural corrige as dificuldades da perspectiva durkheimiana, que reconduzindo os factos sociais a representações colectivas, considerava a dimensão individual e a dimensão social como objectos exteriores um ao outro. Para Lévi-Strauss, pelo contrário: "Les faits sociaux ne sont ni des choses, ni des idées, ce sont des structures". ${ }^{68}$ A Gestalt: designava

les configurations du champ perceptif, ces totalités articulées par certaines lignes de force, et où tout phénomène tient d'elles sa valeur locale. ${ }^{69}$.

Quando passa a ser utilizada também em linguística, a noção de estrutura mantém o seu carácter de sistema concreto, de sistema encarnado:

Quand il disait que le signe linguistique est diacritique - qu'il n'opère que par sa différence, par un certain écart entre lui et les autres signes, et non pas d'abord en évoquant une signification positive, - Saussure rendait sensible l'unité de la

${ }^{64}$ Ibid., p. 118. Sobre a relação entre inconsciente psicanalítico e percepção, e sobre o valor ontológico que esta relação assume no pensamento do último Merleau-Ponty, cf. Carbone, Una deformazione senza precedenti. Marcel Proust e le idee sensibili. Macerata, Quodlibet, 2004, pp. 109 ss.

${ }^{65}$ Merleau-Ponty, M., L'institution-La passivité, ed. cit., p. 118.

66 Ibid.

67 Ibid., p. 121 .

68 Ibid., p. 146.

69 Ibid. 
langue au-dessous de la signification explicite, une systématisation qui se fait en elle avant que le principe idéal en soit connu. ${ }^{70}$

A estrutura é, por um lado, um princípio organizador que articula os elementos que a compõem produzindo um sentido. Mas, ao mesmo tempo, este sentido não é uma essência que possa ser abstraída dos elementos do sistema, "ce sens qu'elle porte est pour ainsi dire un sens lourd". É por esta razão que a estrutura, continua Merleau-Ponty, se recusa a ser interpretada como se se tratasse de uma ideia platónica, de um arquétipo eterno, porque não retira ao mundo social a sua espessura.

Aqui Merleau-Ponty formula uma pergunta que deixa transparecer uma certa tomada de distância face às posições mais deterministas de Lévi-Strauss:

Finirons-nous par trouver, comme le voudrait la sociologie proprement dite, des invariants universels? C'est à voir. ${ }^{71}$

Um distanciamento discreto que emerge também quando o filósofo admite que na análise das estruturas mais complexas "il peut être nécessaire de recourir à une expression quasi mathématique" e que "on peut même rêver d'un tableau périodique des structures de parenté comparable au tableau des éléments chimiques de Mendeleieff'. ${ }^{72}$

A antropologia indica-nos, aliás, uma maneira diversa de entender o universal:

non plus l'universel de surplomb d'une méthode strictement objective, mais comme un universel latéral dont nous faisons l'acquisition par l'expérience ethnologique, incessante mise à l'épreuve de soi par l'autre et de l'autre par soi. ${ }^{73}$

A noção de estrutura, conclui, estabelece todo um novo regime de pensamento e, mostrando-nos como o ser humano é "excentrique à lui-même", indica uma maneira de ultrapassar a correlação de sujeito e objecto que caracteriza toda a filosofia tradicional. ${ }^{74}$ As análises concretas de Lévi-Strauss são mais ricas e fecundas do que os princípios filosóficos, de cariz objectivista e racionalista, aos quais recorre para as interpretar.

Na sua intervenção 'Colloque sur le mot structure dans les sciences humaines et sociales', que aconteceu em Janeiro de 1961, Merleau-Ponty

70 Ibid.

71 Ibid.

72 Ibid., p. 148, sublinhados nossos. Lévi-Strauss formula a intenção de poder obter, graças ao cálculo electrónico, "une sorte de tableau périodique des structures linguistiques, comparable à celui des éléments dont la chimie moderne est redevable à Mendeleeff" no artigo "Langage et société", cit., p. 66. 
observa que a noção de estrutura é passível de diferentes interpretações. Por um lado, pode ser "«tirée» vers le haut" e ser apenas um substituto da essência, como acontece, na sua opinião, nos trabalhos de Ruyer. ${ }^{75}$ Por outro, a estrutura pode ser "«tirée» vers le bas" reduzida à mera constatação de uma certa distribuição de dados, "une pure connexion de faits enregistrés", como acontece no estruturalismo linguístico norte-americano. Porém, existe uma terceira forma de encarar a estrutura, que se situa justamente entre estas duas e que é a mais produtiva do ponto de vista filosófico:

Dans la pensée structuraliste on découvre une nouvelle manière de voir l'Être; il s'agit d'un principe intérieur d'une distribution observable; ce n'est pas une unité que l'on peut se représenter et encore moins que nos sens peuvent appréhender. ${ }^{76}$

Merleau-Ponty defende explicitamente a existência de uma continuidade entre o gestaltismo e a linguística saussuriana, o que explica, pelo menos em parte, a sua leitura 'transgressiva' das teorias apresentadas no Cours. Mas ao mesmo tempo, como observou justamente Mauro Carbone, as análises de Saussure conduzem o filósofo a introduzir uma variante plenamente diacrítica à sua elaboração da noção de Gestalt, ao desenvolver a relação de figura-fundo no sentido de um 'écart', de uma pura diferença sem termos positivos. ${ }^{77}$

Isto é, Merleau-Ponty encontra no estruturalismo de matriz saussuriana, interpretado com certeza de forma digamos "original", a possibilidade de estender as suas considerações sobre a percepção à linguagem, ao mundo social e a história. Ou, melhor, encontra um plảno onde possa ser pensada uma continuidade entre percepção, linguagem, mundo social e história, resolvendo algumas dificuldades

Mas podemos questionarmo-nos então até que ponto a reflexão que Merleau-Ponty faz sobre a história nos últimos anos da sua vida fosse diferente da perspectiva que Sartre elabora em Critique de la raison dialectique. Afinal, para além das divergências políticas, não se trata, também para Merleau-Ponty, de reconduzir os métodos das ciências humanas às suas raízes vividas, de encontrar a síntese entre individual e colectivo na dialéctica da praxis humana, de apontar a história como perspectiva de totalização de uma verdade em per-

75 Ibid., p. 154. Merleau-Ponty refere a este propósito Ruyer, Raymond, Esquisse d'une Philosophie de la Structure. Paris, Paris 1930.

76 Ibid.

77 "dans la langue il n'y a que des différences sans termes positifs" (Saussure, Cours de linguistique génerale, cit., p. 166), cf. mais acima, pp. 50 e ss. 
pétuo movimento? Até que ponto a antropologia estrutural e histórica de que fala Sartre se diferencia da história estrutural de que fala Merleau-Ponty? ${ }^{78}$ Merleau-Ponty tinha observado, já em 1945, que as análises que Sartre desenvolveu em L'être et le néant são demasiado antitéticas e não permitem uma correcta apreciação do mundo social:

Il faut analyser l'engagement, le moment où les conditions subjectives et les conditions objectives de l'histoire se nouent les unes sur les autres, le mode d'existence de la classe avant la prise de conscience, bref le statut du social et le phénomène de la coexistence. Cette théorie du social, L'être et le néant ne nous la donne pas encore. ${ }^{79}$

Mas não é, no fundo, esta teoria do social que Sartre elabora precisamente em Critique de la raison dialectique? Não empreende ele, juntamente com a sua adesão ao comunismo, uma verdadeira fenomenologia do grupo? E quando remete a síntese da pluralidade individual para uma história como "totalișation en cours", ${ }^{80}$ não estará a apontar para algo próximo ao que Merleau-Ponty dizia quando definia a filosofia como "la conscience qu'il nous faut garder de la communauté ouverte et successive des alter ego vivant, parlant, et pensant" 81

Num artigo publicado em 1997 na revista Les temps modernes, volta-se a considerar a polémica que opôs Lévi-Strauss e Sartre nos primeiros anos da década de ' $60 .^{82}$ Sartre -em Questions de méthode e ainda, de forma mais extensa e aprofundada, em Critique de la raison dialectique ${ }^{83}$ - recusa o dogmatismo do materialismo dialéctico soviético e do estalinismo, que retira qualquer direito à dimensão individual, e apela a um marxismo autêntico que deveria, pelo contrário, integrar a perspectiva existencialista. Tal objectivo será alcançado unicamente se o marxismo utilizar com eficácia as contribuições vindas da psicanálise, da sociologia e das ciências humanas em geral. No entanto, as ciências humanas tendem a privilegiar os sistemas e as estruturas, isto é, a razão analítica, que isola mecanicamente os elementos que compõem os fenómenos que estuda, abstraindo-os do seu contexto. É então necessário, para Sartre, que os instrumentos metodológicos das ciências humanas e sociais sejam reformulados à luz da razão dialéctica, ou seja, reinseridos dialectica-

78 Sartre, Jean-Paul, Critique de la raison dialectique, ed. cit., p. 14; Merleau-Ponty, M., De Mauss à Claude Lévi-Strauss, ed. cit., p. 155.

79 Merleau-Ponty, M., "La querelle de l'existentialisme", Les Temps Modernes 2, nov. 1945, pp. 344-356 e, depois, in Merleau-Ponty, M., Sens et non-sens, ed. cit., pp. 89-90.

${ }^{80}$ Sartre, Jean-Paul, Critique de la raison dialectique, ed. cit., p. 135.

81 Ibid., p. 138.

82 Delacampagne, Christian/Traimond, Bertrand, "La polémique Sartre/Lévi-Strauss revisitée", Les Temps Modernes LiII, nov.-déc. 1997, n. 596, pp. 10-31. Para análise dos elementos filosóficos essenciais do debate entre Lévi-Strauss e Sartre, cf. Cunha, Tito Cardoso e, "A Natureza e a História", Antropologia e Filosofia, cit., pp. 113-126.

${ }^{83}$ Sartre, Jean-Paul, Critique de la raison dialectique, cit. 
mente no mundo humano a que pertencem, mundo humano que é entendido fundamentalmente como a articulação da praxis individual à praxis dos outros indivíduos:

si quelque chose comme une Vérité doit pouvoir exister dans l'anthropologie, elle doit être devenue, elle doit se faire totalisation. Il va sans dire que cette double exigence définit ce mouvement de l'Être et de la connaissance (ou de la compréhension) qu'on nomme depuis Hegel «dialectique». [...] une telle totalisation est perpétuellement en cours comme Histoire et comme Vérité historique. ${ }^{84}$

No capítulo final de La pensée sauvage, intitulado 'Histoire et dialectique', ${ }^{85}$ Lévi-Strauss faz uma crítica cerrada às posições de Sartre, considerado como o maior representante daquela sobrevalorização da história que é típica do etnocentrismo ocidental. No seu livro, Sartre constrói as figuras da sua antropologia filosófica, que pretende fundamentar todas as possíveis relações humanas historicamente determinadas, inspirando-se em episódios da Revolução Francesa: a revolta do bairro St. Antoine, a tomada da Bastilha, o Juramento, o Terror etc. Isto, para Lévi-Strauss, significa que a Revolução continua a ter a função de um paradigma que orienta o presente. Um paradigma necessário do ponto de vista prático, mas que não goza de qualquer prioridade do ponto de vista teórico. Mais cedo ou mais tarde será substituído por outro igualmente legítimo. E, como se não bastasse, por cada um destes eventos paradigmáticos, há uma infinidade de perspectivas possíveis; uma Revolução vivida por um jacobino não é igual à Revolução vivida por um aristocrata:

Il faut donc choisir entre deux partis: soit retenir principalement l'une d'elles ou une troisième (car il y en a une infinité), et renoncer à chercher dans l'histoire une totalisation d'ensemble de totalisations partielles; soit reconnaître à toutes une égale réalité: mais seulement pour découvrir que la Révolution française telle qu'on en parle n'a pas existé ${ }^{86}$

Não que Lévi-Strauss tencione negar a realidade da Revolução Francesa como acontecimento, evidentemente. Em última análise são as posições que já constatámos em Race et histoire. ${ }^{87}$ Ou seja, que o sentido deste acontecimento, como de qualquer outro, é dependente da perspectiva do observador e portanto essencialmente inesgotável. As reflexões de Sartre mostram, de acordo com o antropólogo, que o sentido da história se constitui sempre como "histoire-pour", mas tal significa então que "Une histoire vraiment totale se neutraliserait elle-même: son produit serait égal à zéro". ${ }^{88} \mathrm{O}$ autor da Critique de

\footnotetext{
${ }^{84}$ Ibid., p. 14.

${ }^{85}$ LévI-STrauss, La pensée sauvage, cit., pp. 324 e segs.

${ }^{86}$ Ibid., p. 342.

${ }^{87}$ Cf. mais acima, pp. 205 e ss.

${ }^{88}$ Lévi-Strauss, La pensée sauvage, cit., p. 341.
} 
la raison dialectique parece ter entendido apenas metade do que Marx e Freud ensinaram. Ou seja, para compreender o homem è preciso posicionar-se do ponto de vista do sentido. E até aqui, continua Lévi-Strauss, estamos todos de acordo.

No entanto, Marx e Freud seguidamente chamaram a atenção para o facto que "ce sens n'est jamais le bon: les superstructures sont des actes manqués qui ont socialement «réussi»". ${ }^{89} \mathrm{O}$ sentido mais 'verdadeiro' nunca poderá pertencer à consciência histórica e a totalização de um certo horizonte histórico não possui nenhuma fundamentação intrínseca. Por consequência, conclui Lévi-Strauss, Sartre

se situe donc vis-à-vis de l'histoire comme les primitifs vis-à-vis l'éternel passé: dans le système de Sartre, l'histoire joue très précisément le rôle d'un mythe. ${ }^{90}$

É verdade, que para Sartre o sujeito e a consciência se mantêm a referência essencial continua. $\mathrm{O}$ fundamento da história e da sua compreensão reside na estrutura teleológico-consciente da praxis individual: "toute dialectique historique repose sur la praxis individuelle en tant que celle-ci est déjà dialectique". ${ }^{91} \mathrm{E}$ ainda "Le seul fondement concret de la dialectique historique c'est la structure dialectique de l'action individuelle. "92

Mas se exceptuarmos este aspecto, a história parece oferecer tanto para Merleau-Ponty como para Sartre um plano de totalização possível. Como podemos ler em Les adventures de la dialectique:

Quand le sujet se reconnaît dans l'histoire et reconnaît l'histoire en lui-même, il ne domine pas le tout comme le philosophe hégélien, mais du moins il est engagé dans une tâche de totalisation. ${ }^{93}$

Contudo, a posição merleau-pontiana perante a história foi objecto de uma contínua reelaboração, e em documentos dos últimos anos encontramos um tom diferente. Se em 1951 escreve que a filosofia é "la conscience qu'il nous faut garder de la communauté ouverte et successive des alter ego vivant, parlant, et pensant", em 1959, numa "note de travail" de Le visible et l'invisible, considera que "il s'agit de saisir ce qui à travers la communauté successive et simultanée des sujets parlants veut, parle, et finalement pense". ${ }^{94}$

Mesmo enquanto Sartre, respondendo de uma certa forma às críticas de Merleau-Ponty, afirma a prioridade da dialéctica e continua a apontar para

89 Ibid., p. 336.

90 Ibid.

91 Ibid., p. 165.

92 Ibid., pp. 280.

93 Merleau-Ponty, M., adventures de la dialectique, cit., p. 48.

94 Merleau-Ponty, M., "Note de travail", de Fevereiro de 1959, in Le Visible et l'Invisible, cit., p. 230 , sublinhado nosso. 
uma futura conciliação entre todas as contradições, Merleau-Ponty está cada vez mais empenhado em pensar uma dialéctica sem síntese. ${ }^{95}$ E efectivamente começa a repensar e até certo ponto a colocar em discussão a própria noção de dialéctica, que quando é afirmada como tese que resulta numa filosofia dialéctica, deixa precisamente por isso de ser autenticamente dialéctica, tornando-se numa dialéctica embalsamada ${ }^{96}$ È justamente do falhanço da dialéctica afirmada tematicamente que o filósofo retira a noção de uma "intersubjectivité non perspective, mais verticale, qui est, étendue au passé, éternité existentielle, esprit sauvage". 97

E é neste sentido que numa "note de travail" de Junho de 1960, que certamente já se refere à Critique de la raison dialectique, Merleau-Ponty considera necessário

Opposer à une philosophie de l'histoire comme celle de Sartre [...] non pas sans doute une philosophie de la géographie (il serait aussi vain de prendre pour axe la rencontre de la praxis individuelle avec l'en Soi spatial que sa rencontre avec l'inerte, les «relations entre personnes» médiatisées par l'espace que les relations entre personnes médiatisées par le temps), -mais une philosophie de la structure qui, à la vérité, se formera mieux au contact de la géographie qu'au contact de l'histoire. Car l'histoire est trop immédiatement liée à la praxis individuelle, à l'intériorité, elle cache trop son épaisseur et sa chair pour qu'il ne soit pas facile d'y réintroduire toute la philosophie de la personne. ${ }^{98}$

Torna-se difícil não constatar aqui uma proximidade considerável com as posições de Lévi-Strauss, o qual pouco tempo depois escreve em La pensée sauvage:

L'ethnologue respecte l'histoire, mais il ne lui accorde pas une valeur privilégiée. Il la conçoit comme une recherche complémentaire de la sienne: l'une déploie l'éventail des sociétés humaines dans le temps, l'autre dans l'espace... Ce rapport de symétrie entre l'histoire et l'ethnologie semble être rejeté par des philosophes qui contestent, implicitement ou explicitement, que l'étalement dans l'espace et la succession dans le temps offrent des perspectives équivalentes. On dirait qu'à leurs yeux la dimension temporelle jouit d'un prestige spécial, comme si la diachronie fondait un type d'intelligibilité, non seulement supérieur à celui qu'apporte la synchronie, mais surtout d'ordre plus spécifiquement humain. ${ }^{99}$

No entanto, precisamos ter presente, como observa justamente Guido D. Neri, que quando Merleau-Ponty formula a ideia de uma prevalência da geo-

${ }^{95}$ Neri, Guido D., "Storia e possibilita", pp. 219-220. Cf. também Barbaras, R., De l'être du phénoméne, cit., pp. 135 ss.

${ }_{96}$ Merleau-Ponty, M., "Note de travail", de Fevereiro de 1959, in Le Visible et l'Invisible, cit., p. 229

97 Ibid.

98 Ibid., p. 312.

${ }^{99}$ Lévi-Strauss, La pensée sauvage, cit., p. 339. 
grafia, ou seja da dimensão sincrónica, está a referir-se às analises de Husserl conhecidas como Umsturz der kopernikanishen Lehre, e também ao facto que "la Terre comme Ur-Arche met en évidence l'Urhistorie charnelle". O objectivo da reflexão do filósofo não consistia portanto em desfavorecer a diacronia em prol da sincronia, nem de limitar-se a postular uma relação dialéctica, mas consistia em procurar captar o "nexus" que as une entre si, ou seja, o "chiasme", termo chave de Le visible et l'invisible:

En fait il s'agit de saisir le nexus, - ni «historique» ni «géographique», - de l'histoire et de la géologie transcendantale, ce même temps qui est espace, ce même espace qui est temps, que j'aurai retrouvé par mon analyse du visible et de la chair, l'Urstiftung simultanée de temps et espace qui fait qu'il y a un paysage historique et une inscription quasi géographique de l'histoire. ${ }^{100}$

E é nesta passagem de uma relação dialéctica a uma relação de plena reversibilidade entre diacronia e sincronia que Merleau-Ponty configura a noção de "histoire structurale" ou "verticale", isto é, de uma história que não reduz o mundo humano a uma sequência serial de acontecimentos e decisões, mas que reconhece "que le mythe, le temps légendaire hantent toujours, sous d'autres formes, les entreprises humaines". ${ }^{101}$

\section{ABSTRACT}

In one of the working notes from the Visible and the Invisible, Merleau-Ponty expresses the intention of resuming his critique of Lévi-Strauss's notion of Gestatung in a future version of the text. The recent publication of the notes from the course at the College de France (1954-55), and particularly the first of them regarding " $L$ 'institution dans l'histoire personelle et publique", allows a more thorough understanding of that otherwise rather obscure reference. In this paper, we track Merleau-Ponty's critique of the anthropologist's theory of history in the courses on institution as well as in other texts of the same period (and particularly relevant is the reference to Les aventures de la dialectique). The French philosopher pursues a conceptual path that may move beyond the radical relativism professed by the Lévi-Strauss, which is nothing but a supplement of natural objectivism, and aims at a "relativization of the relative". We thus see how Merleau-Ponty focuses this question on the notion of "historical" and "social" perception, suggesting a "perceptive" reading of the categories proposed by Lévi-Strauss. We believe that this particular phase of the merleau-pontyan reflection on history is a step of the greater importance in the theoretical path towards the ontological inquiries of his last works.

${ }^{100}$ Merleau-Ponty, M., "Note de travail", de Fevereiro de 1959, in Le Visible et l'Invisible, cit., p. 312.

${ }^{101}$ Merleau-Ponty, M., De Mauss à Claude Lévi-Strauss, cit., p. 155. 
